\title{
Investigating the Financial Awareness and Behaviors of Veterinary Medical Students
}

\author{
Amy M. Snyder ${ }^{1} \&$ Kenneth D. Royal ${ }^{1}$ \\ ${ }^{1}$ Department of Clinical Sciences, College of Veterinary Medicine, North Carolina State University, Raleigh, NC, \\ USA \\ Correspondence: Kenneth D. Royal, Department of Clinical Sciences, College of Veterinary Medicine, North \\ Carolina State University, 1060 William Moore Dr., Raleigh, NC, 27607, USA. Tel: 1-919-513-6100. E-mail: \\ kdroyal2@ncsu.edu
}

Received: April 5, 2016

Accepted: April 21, 2016

Online Published: June 25, 2016

doi:10.5539/ijef.v8n7p201

URL: http://dx.doi.org/10.5539/ijef.v8n7p201

\begin{abstract}
A sample of veterinary medical students were administered a modified version of the Financial Fitness Quiz (FFQ) to gain insights about current veterinary students money management behaviors (e.g., developing financial goals, having a spending plan, accumulating savings, etc.). Results demonstrate students possess a general awareness and conscientiousness toward personal finance. In some cases, veterinary students engaged in positive financial behaviors at a higher rate than average consumers in the United States, and most reported having more cash on hand to cover an emergency than average consumers in the United States. While students generally appear to understand the negative impact of debt, results indicate most students do not fully appreciate the value of personal budgeting or annual calculations of net worth.
\end{abstract}

Keywords: economics, education, teaching, behavioral finance, finance

\section{Introduction}

The rising cost of higher education has gained much attention in recent years. According to the U.S. Department of Education (Snyder \& Dillow, 2015), the cost of undergraduate tuition, room and board at public institutions rose $39 \%$ between 2002-03 and 2012-13. The cost of a post-graduate education has also risen. In the past 15 years, students at the 28 U.S. veterinary colleges have experienced a nearly $250 \%$ increase in the mean cost of tuition and fees (American Veterinary Medical Association, 2015). Complicating matters, during the years 2008 to 2012 starting veterinary salaries fell and remain approximately $\$ 3,700$ off the longer term trend (American Veterinary Medical Association, 2015).

In 2015, the American Veterinary Medical Association's (AVMA) Veterinary Economic Division published a series of economic reports based on data collected from the AVMA's Senior Survey, Employment Survey and Veterinary Compensation Survey. The third report in this series, the 2015 AVMA Report on Veterinary Debt and Income, focused on the challenges faced by new graduates. The report identified two Key Performance Indicators (KPI) for the veterinary profession: Debt-to-Income Ratio (DIR) and Net Present Value of the DVM degree (NPV). DIR is an indicator of the financial health of a veterinarian entering the profession. For 2014, the DIR index value was 2.05, indicating a level of debt slightly greater than two times starting income (American Veterinary Medical Association, 2015). NPV is an indicator of the lifelong value of a veterinary medical degree. It is a measure of the added value of a veterinary degree as compared to what might have been gained from a bachelor's degree alone. For 2014, the average NPV of a veterinary degree for women and men was \$71,462 and $\$ 41,480$, respectively (Knippenberg, 2015).

DIR and NPV are important KPIs as both can be influenced in part by the actions of veterinary students. Specifically both DIR and NPV can be influenced by the training cost incurred by and the financial acumen of veterinary students (American Veterinary Medical Association, 2015). NPV can also be influenced by career path, work/life balance and retirement age chosen by future veterinarians, as well as socioeconomic factors (American Veterinary Medical Association, 2015). However, at present there are extremely little data focused on understanding veterinary students' financial behaviors. Thus, the purpose of this study was to investigate the 'financial fitness' of current veterinary medical students at a large, public university so as to reveal students' awareness and behaviors as it pertains to matters of personal finance. 


\section{Method}

\subsection{Course Description}

Success in Veterinary Practice is a two week intensive course focused on the non-medical aspects of veterinary medicine. The course explores topics such as starting and building a practice, communicating value, leadership, managing a successful veterinary team, understanding and negotiating employment contracts, personal finance and loan repayment options, practice finance and financial benchmarking. Historically, students self-select to take the course during the fall of either their first, second or third year of veterinary school. However, due to curricular changes, all second and third year students that had not previously taken the course were required to take it in the fall of 2015. Veterinary students enrolled in the school's dual DVM/PhD program were also given the opportunity to enroll in the course.

\subsection{Participants}

A survey was administered on the first day of class to all 78 students enrolled in the Success in Veterinary Practice course as part of an assignment to discern students' current levels of financial fitness. All 78 students completed the survey, resulting in a $100 \%$ response rate. A complete breakdown of student demographic characteristics are presented in Table 1.

Table 1. Demographic characteristics of sample

\begin{tabular}{|c|c|}
\hline Variable & No. $(\%)$ \\
\hline \multicolumn{2}{|l|}{ Sex } \\
\hline Male & $14(17.9)$ \\
\hline Female & $64(82.1)$ \\
\hline \multicolumn{2}{|l|}{ Race/Ethnicity } \\
\hline Black or African American & $3(3.8)$ \\
\hline Hispanic or Latino & $3(3.8)$ \\
\hline White & $65(83.3)$ \\
\hline Other/Not Specified & $7(9.0)$ \\
\hline \multicolumn{2}{|l|}{ Class } \\
\hline 2017 & $17(21.8)$ \\
\hline 2018 & $55(70.5)$ \\
\hline Dual degree (DVM/PhD) & $6(7.7)$ \\
\hline \multicolumn{2}{|l|}{ Age $(y)$} \\
\hline Mean (SD) & $25.6(3.0)$ \\
\hline Median & 25 \\
\hline Range & $21-36$ \\
\hline \multicolumn{2}{|l|}{ Annual Household Income } \\
\hline Less than $\$ 10,000(1)$ & $37(47.4)$ \\
\hline$\$ 10,000-\$ 24,999(2)$ & $15(19.2)$ \\
\hline$\$ 25,000-\$ 49,999(3)$ & $14(17.9)$ \\
\hline$\$ 50,000-\$ 74,999(4)$ & $8(10.3)$ \\
\hline$\$ 75,000-\$ 99,999(5)$ & $2(2.6)$ \\
\hline$\$ 100,000$ or more $(6)$ & $2(2.6)$ \\
\hline
\end{tabular}

\subsection{Instrumentation}

Students were administered a modified version of the Financial Fitness Quiz (FFQ) (O'Neill \& Xiao, 2003; 2006). The FFQ measures money management behaviors, such as developing financial goals, having a spending plan, accumulating savings, etc. The instrument consisted of 15 items using a five point frequency scale (1=Never; 2=Seldom; 3=Sometimes; 4=Usually; and 5=Always). Three supplemental items with 'yes/no' responses were also included. A listing of items presented to students are available in Tables 2 and 3. 
Table 2. Items appearing on the modified financial fitness quiz (frequency scale)

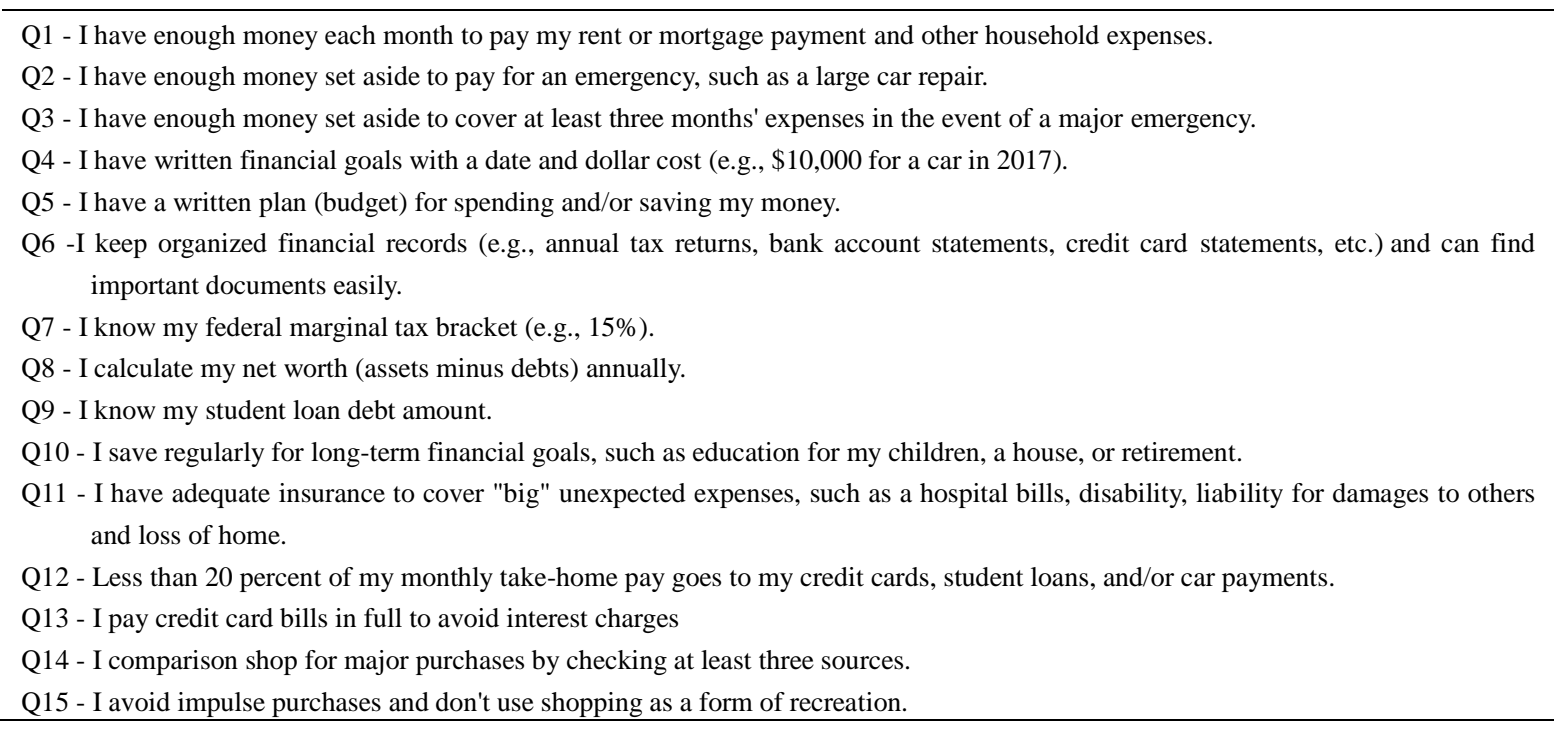

Table 3. Supplemental items (yes/no scale)

Q16 - I have a bank checking account (or credit union share draft account) with which to pay bills.

Q17 - I have a personal investment account for retirement (e.g., 401(k), 403(b), IRA) other than a retirement plan by my employer.

Q18 - I have a current will.

\subsection{Data Analysis}

Because the modified version of the FFQ was used for the first time, and the sample frame differed slightly from typical administrations of the traditional FFQ, it was necessary to subject the instrument to a psychometric validation procedure to evaluate its psychometric properties. The purpose of this preliminary step was essentially to discern the degree to which the findings would be deemed accurate and trustworthy. The primary data analysis for substantive results, however, consisted of traditional statistical procedures (e.g., descriptive statistics, t-tests, etc.).

\section{Results}

\subsection{Validity and Reliability Evidence}

The Rasch Rating Scale Model (Andrich, 1978) was utilized to evaluate the psychometric quality of the instrument and its functioning relative to the veterinary student sample frame. Messick's (1989) framework for validity was used to evaluate the psychometric properties of the instrument. Because all 78 students completed the survey, issues of non-response bias were negated. Cronbach's alpha reliability estimates for the 15 items comprising the modified FFQ yielded a value of .735, indicating moderately reproducible measures (Royal \& Hecker, 2015). This speaks to the generalizability aspect of validity. A Rasch-based principal components analysis (PCA) of standardized residual correlations indicated 54.8\% of the variance was explained by the measures. The largest secondary dimension possessed an eigenvalue of 1.68 , indicating the strength of a secondary dimension was about 2 items in magnitude. This lends support to a primary dimension being measured and speaks to the substantive aspect of validity. Infit and outfit mean square fit statistics for each item fell within the recommended range of 0.6-2.0 (Wright \& Linacre, 1994). Additionally, point-measure correlations ranged from .30-.66, indicating the items possessed adequate discriminatory capabilities. These pieces of evidence speak to the content aspect of validity. Finally, rating scale category thresholds $(-2.04,-.64, .09 . .73$, and 1.75) advanced in a stepwise manner (Linacre, 2002), thus lending support to the structural aspect of validity.

\subsection{Overall Results}

Descriptive statistics were produced to indicate the frequency with which students endorsed each item. To aid with reporting and interpretation, the 5-point frequency scale was collapsed into a 3-point scale. Complete results are presented in Table 4 . 
Table 4. Financial behavior items

\begin{tabular}{lccc}
\hline \multicolumn{1}{c}{ Item } & Always or Usually & Sometimes & Seldom or Never \\
\hline Q1 - Enough rent/bill money & $\mathrm{n}(\%)$ & $\mathrm{n}(\%)$ & $\mathrm{n}(\%)$ \\
Q2 - Enough money for an emergency (e.g., large car repair) & $76(97.44)$ & $0(0.00)$ & $2(2.56)$ \\
Q3 - Enough money to cover 3+ months' expenses & $53(67.95)$ & $15(19.23)$ & $10(12.82)$ \\
Q4 - Written financial goals & $36(46.15)$ & $13(16.67)$ & $29(37.18)$ \\
Q5 - Written plan (budget) for spending/saving money & $7(8.97)$ & $18(23.08)$ & $53(67.95)$ \\
Q6 - Organized financial records & $28(35.90)$ & $19(24.36)$ & $33(42.31)$ \\
Q7 - Know my federal tax bracket & $50(64.10)$ & $16(20.51)$ & $12(15.38)$ \\
Q8 - Calculate my net worth (assets minus debts) annually & $9(11.54)$ & $11(14.10)$ & $58(74.36)$ \\
Q9 - Know my student loan debt amount. & $14(17.95)$ & $7(8.97)$ & $57(73.08)$ \\
Q10 - Save regularly for long-term financial goals & $70(89.74)$ & $3(3.85)$ & $5(6.41)$ \\
Q11 - Adequate insurance to cover "big" unexpected expenses & $22(28.21)$ & $21(26.92)$ & $35(44.87)$ \\
Q12 - Less than 20\% of monthly pay goes to debts/loans & $63(80.77)$ & $5(6.41)$ & $10(12.82)$ \\
Q13 - Pay credit card bills in full & $28(35.90)$ & $16(20.51)$ & $36(46.15)$ \\
Q14 - Comparison shop for major purchases & $64(82.05)$ & $10(12.82)$ & $4(5.13)$ \\
Q15 - Avoid impulse purchases & $61(78.21)$ & $12(15.38)$ & $5(6.41)$ \\
\end{tabular}

Three supplemental items utilizing a 'yes/no' format were also included. Students were asked: 1) if they have a bank checking account. Of the 78 students, 76 (97.4\%) indicated 'yes' and $2(2.6 \%)$ indicated 'no'; (2) if they have a personal investment account for retirement. Seventeen (21.8\%) indicated 'yes' and $61(78.2 \%)$ indicated 'no'; and (3) if they have a current will. Only $5(6.4 \%)$ indicated 'yes' and $73(93.6 \%)$ indicated 'no'.

\subsection{Results by Demographic Characteristics}

With regard to age, older students, as expected, tend to report higher income levels than younger students (Kendall's $\tau=.27, p=.001$ ). Class year revealed no discernible differences in household income. Additionally, no discernible differences were observed for financial behavior with regard to race and ethnicity.

A comparison of financial behaviors by sex indicated females $(\mathrm{M}=1.69, \mathrm{SD}=1.01)$ were more likely than males ( $\mathrm{M}=1.07, \mathrm{SD}=0.27)$ to "pay credit card bills in full to avoid interest charges", $t(76)=-2.263, p<0.000)$. A Cohen's $d$ effect size (Cohen, 1992) estimate of .83 indicates the magnitude of this difference is "large" in terms of practical significance. A complete breakdown of results by sex are presented in table 5 .

Table 5. Financial behavior by sex

\begin{tabular}{|c|c|c|c|}
\hline Item & $\begin{array}{c}\text { Male } \\
\text { M (SD) }\end{array}$ & $\begin{array}{l}\text { Female } \\
\text { M (SD) }\end{array}$ & $p$ \\
\hline Q1 - Enough rent/bill money & $1.14(0.36)$ & $1.39(0.73)$ & .070 \\
\hline Q2 - Enough money for an emergency (e.g., large car repair) & $1.64(1.08)$ & $2.28(1.12)$ & .056 \\
\hline Q3 - Enough money to cover 3+ months' expenses & $2.50(1.45)$ & $3.06(1.40)$ & .181 \\
\hline Q4 - Written financial goals & $3.57(1.34)$ & $4.05(0.93)$ & .226 \\
\hline Q5 - Written plan (budget) for spending/saving money & $3.57(1.56)$ & $3.11(1.26)$ & .238 \\
\hline Q6 - Organized financial records & $2.50(1.29)$ & $2.30(1.06)$ & .535 \\
\hline Q7 - Know my federal tax bracket & $3.64(1.28)$ & $4.30(1.16)$ & .065 \\
\hline Q8 - Calculate my net worth (assets minus debts) annually. & $3.50(1.65)$ & $4.30(1.27)$ & .108 \\
\hline Q9 - Know my student loan debt amount. & $1.50(1.09)$ & $1.64(0.90)$ & .611 \\
\hline Q10 - Save regularly for long-term financial goals & $3.43(1.51)$ & $3.31(1.37)$ & .778 \\
\hline Q11 - Adequate insurance to cover "big" unexpected expenses & $1.64(0.84)$ & $1.98(1.30)$ & .352 \\
\hline Q12 - <20\% of monthly pay goes to debts/loans & $3.43(1.60)$ & $3.31(1.39)$ & .784 \\
\hline Q13 - Pay credit card bills in full & $1.07(0.27)$ & $1.69(1.01)$ & .000 \\
\hline Q14 - Comparison shop for major purchases & $2.07(1.14)$ & $1.78(0.97)$ & .328 \\
\hline Q15 - Avoid impulse purchases & $1.86(0.86)$ & $2.09(0.92)$ & .382 \\
\hline
\end{tabular}

With regard to the supplemental items, 63 of the 64 females (98.4\%) reported have a checking account compared to 13 out of 14 males $(92.9 \%)$. With regard to having a personal investment account for retirement, 15 of 64 
(23.4\%) females answered 'yes' compared to 2 of $14(14.3 \%)$ of males. With regard to having a current will, 4 of $64(6.3 \%)$ females indicated 'yes' compared to 1 of $14(7.1 \%)$ males.

\section{Discussion}

Results of the psychometric validation were evaluated by way of Messick's framework for validity. Validity evidence was available to support the substantive, content, structural and generalizability aspects of construct validity. Collectively, the psychometric validation process provided a great deal of evidence that the findings from this study are valid and reproducible.

With regard to substantive findings, most students indicated they usually or always: 1) have enough money to pay rent/bills $(97.44 \%), 2)$ know their student loan debt amount $(89.74 \%)$, 3) pay their credit card bills in full $(82.05), 4)$ have adequate insurance to cover "big" unexpected expenses $(80.77 \%)$, and 5) comparison shop for major purchases $(78.21 \%)$. These findings demonstrate a general awareness and conscientiousness toward personal finance amongst participants. In some cases, students engaged in positive financial behaviors at a higher rate than average consumers in the United States. For example, according to the 2015 Consumer Financial Literacy Survey, only $49 \%$ of respondents reported carrying no credit card debit from month to month as compared to $82 \%$ of study participants (National Foundation for Credit Counseling, 2015).

Behaviors that most students indicated they rarely, seldom, or only sometimes exhibit include: 1) preparing written financial goals $(91.02 \%)$, 2) knowing their federal tax bracket $(88.46 \%)$, 3) calculating their net worth (assets minus debts) annually (82.05\%), 4) saving regularly for long-term financial goals (71.79\%), 5) having a written plan (budget) for spending/saving money $(66.67 \%)$, 6) devoting less than $20 \%$ of monthly pay to debts/loans (66.67\%), and 7) having enough money to cover more than 3 months' expenses (53.84\%). In many ways, some of these behaviors are to be expected given these students do not currently have full-time employment, and most never have (based on internal College of Veterinary Medicine data). While the absence of written financial goals and monthly budgeting does not necessarily equate to being fiscally irresponsible, research on budgeting has indicated that one's beliefs about and management of money can influence spending patterns (Heath \& Soll, 1996). Thus, maintaining written financial goals and a monthly budget would be a desirable practice for students.

Interestingly, only $10 \%$ of students report seldom or never having enough money to cover an emergency. This is in stark contrast to Bankrate's Money Pulse poll in 2014 that showed 63\% of Americans are not prepared for unexpected expenses and only $38 \%$ reported having cash on hand to cover an unexpected emergency room visit or $\$ 500$ car repair (Holland, 2015). This finding may simply be an artifact of the student body who choose to attend this institution (which is one of the nation's least expensive veterinary schools), or it could be indicative of how much money veterinary students ensure they have 'on hand' during the veterinary school years.

With regard to sex, only one item yielded a statistically significant difference. Females $(\mathrm{M}=1.69, \mathrm{SD}=1.01)$ indicated they were more likely than males $(\mathrm{M}=1.07, \mathrm{SD}=0.27)$ to pay credit card bills in full to avoid interest charges $(p<.000)$. This in contrast to a 2015 survey conducted by National Debt Relief (NDR) that found that $63 \%$ of women ages 18 to 24 had credit card debt compared to just $36 \%$ of men (National Debt Relief, 2015). While the age range of consumers in the NDR study was narrower than that of our participants (ages 21-36), our findings may speak to a higher level of awareness as to the consequence of credit card debt.

With regard to one of the supplemental items, $98.4 \%$ of females indicated they have a checking account compared to $92.9 \%$ of males. On the surface, it appears there may be a meaningful difference given the difference in percentages. However, it should be noted that only one male and one female indicated that they did not have a checking account. Thus, the small sample size for the male student group likely gives the impression of greater behavior discrepancy that truly exists.

Research suggest that learning to better manage one's finances and improved budgeting can reduce the likelihood of overconsumption and overspending (Lea, Webley, \& Walker, 1995) Research also suggest that overconsumption and overspendings can be used as reliable indicators of an individual's acceptable level of debt (Davies \& Lea, 1995; Kidwella \& Turrisib, 2004). When these findings are considered together, it suggest that how well individuals manage their finances can impact the amount of debt they accrue. Understanding the current financial behaviors of veterinary students can allow for more targeted intervention with the goal of reducing financial vulnerability. Our findings suggest that students appear to understand the negative impact of debt, as most pay off their credit cards in full each month. However, students do not appear to fully appreciate the value of personal budgeting as most do not engage in monthly budgeting or annual calculations of net worth. Given the evidence of the role budgeting plays in financial health, further investigation into the barriers to budgeting is warranted. Once barrier are identified, we can arrive at a more targeted approach to teaching about 
financial fitness.

\section{References}

American Veterinary Medical Association. (2015). AVMA Report on Veterinary Debt and Income. Washington, DC.

Andrich, D. (1978). A rating formulation for ordered response categories. Psychometrika, 43(4), 561-573. http://dx.doi.org/10.1007/bf02293814

Cohen, J. (1992). A power primer. Psychological Bulletin, 112(1), 155-159.

Davies, E., \& Lea, S. (1995). Student attitudes to student debt. Journal of Economic Psychology, 16(4), 663-679. http://dx.doi.org/10.1016/0167-4870(96)80014-6

Heath, C., \& Soll, J. B. (1996). Mental budgeting and consumer decisions. Journal of Consumer Research, 23(1), 40-52. http://dx.doi.org/10.1086/209465

Holland, K. (2015). 62\% of Americans can't cover unexpected expenses. CNBC, Jan. 7, 2015. Retrieved from http://www.cnbc.com/2015/01/07/

Kidwella, B., \& Turrisib, R. (2004). An examination of college student money management tendencies. Journal of Economic Psychology, 25(5), 601-61. http://dx.doi.org/10.1016/s0167-4870(03)00073-4

Knippenberg, R., Dicks, M. R., Bain, B., \& Dow, M. (2015). Estimating the financial return on a veterinary education. Journal of the American Veterinary Medical Association, 246(4), 422-424. http://dx.doi.org/10.2460/javma.246.4.422

Lea, S., Webley, P., \& Walker, C. M. (1995). Psychological factors in consumer debt: Money management, economic socialization, and credit use. Journal of Economic Psychology, 16, 681-701. http://dx.doi.org/10.1016/0167-4870(95)00013-4

Linacre, J. M. (2002). Optimizing rating scale category effectiveness. Journal of Applied Measurement, 3(1), 85-106.

Messick, S. (1989). Validity. In R. L. Linn (Ed.), Educational Measurement (3rd ed., pp. 13-103). New York: Macmillan.

National Debt Relief. (2015). National Debt Relief Survey of Age and Gender Differences with Credit Usage. New York. Retrieved from https://www.nationaldebtrelief.com/national-debt-relief-survey-of-age-and-gender-differences-with-credit-u sage/

National Foundation for Credit Counseling. (2015). The 2015 Consumer Financial Literacy Survey. Washington, https://www.nfcc.org/wp-content/uploads/2015/04/NFCC_2015_Financial_Literacy_Survey_FINAL.pdf

O’Neill, B. O., \& Xiao, J. J. (2003). Financial Fitness Quiz: A Tool for Analyzing Financial Behavior. Consumer Interests Annual, 49, 1-3. Retrieved from http://njaes.rutgers.edu/money/ffquiz/ffq-research.pdf

O'Neill, B. O., \& Xiao, J. J. (2006). Financial Fitness Quiz Findings: Strengths, Weaknesses, and Disconnects. Journal of Extension, 44(1). Retrieved from http://www.joe.org/joe/2006february/rb5.php

Royal, K. D., \& Hecker, K. G. (2015). Understanding Reliability: A Review for Veterinary Educators. Journal of Veterinary Medical Education, 42(5). http://dx.doi.org/10.3138/jvme.0315-030R

Snyder, T. D., \& Dillow, S. A. (2015). Digest of Education Statistics 2013 (NCES 2015-011). National Center for Education Statistics, Institute of Education Sciences, U.S. Department of Education. Washington, DC.

Wright, B. D., \& Linacre, J. M. (1994). Reasonable mean-square fit values. Rasch Measurement Transactions, $8(3), 370$.

\section{Copyrights}

Copyright for this article is retained by the author(s), with first publication rights granted to the journal.

This is an open-access article distributed under the terms and conditions of the Creative Commons Attribution license (http://creativecommons.org/licenses/by/3.0/). 